\title{
Potential Effects of lodine Supplementation on Inflammatory Processes and Toxin Removal Following COVID-19 Vaccination
}

\author{
Alberto Boretti ${ }^{1}\left(\mathbb{0} \cdot\right.$ Bimal K. Banik $^{1}$ \\ Received: 20 July 2021 / Accepted: 24 October 2021 / Published online: 28 October 2021 \\ (c) The Author(s), under exclusive licence to Springer Science+Business Media, LLC, part of Springer Nature 2021
}

\section{To the Editor,}

Iodine has been reported as a possible agent against COVID19 infection, as well as a possible agent to limit vaccine adverse events. In this letter, we discuss the scientific support for these claims.

Iodine is an essential mineral supplied by the diet or supplements. It is used by the thyroid gland to make thyroid hormones. Iodine is a component of thyroid hormones and an antioxidant, anti-inflammatory, anti-proliferative, and differentiation agent. Iodine contributes to preserving the integrity of organs able to take up iodine, through effects mediated by many different mechanisms or pathways, with direct or indirect actions. It protects the thyroid. It strongly increases the mRNA decay rate.

Thyroid hormones control many functions in the body, which include growth and development, repairing damaged cells, and maintaining healthy metabolism [1] [2]. Iodine can also be used to detoxify toxic compounds and strongly increases the mRNA decay rate [3] [4]. Thus, it may prevent some of the damages caused by COVID-19 mRNA vaccines such as Pfizer or Moderna, both 2 shots, and non-replicating COVID-19 viral vectors vaccines such as Astra-Zeneca, 2 shots, or J\&J's Janssen, 1 shot. The letter to the editor aims to discuss the role of iodine supplementation during the COVID-19 pandemic, with special emphasis on the potential effect on the adverse events from the administration of COVID-19 vaccines.

Mechanistically, iodine from food or supplements is transformed into the negatively charged iodide ion [5]. The human thyroid gland accepts correct amounts required for thyroid hormone preparation the moment iodine enters blood circulation. The excess amount is excreted through urine [6].

\footnotetext{
Alberto Boretti

a.a.boretti@gmail.com

1 Deanship of Research, Prince Mohammad Bin Fahd University, Al-Khobar 31952, Saudi Arabia
}

The average urinary iodine concentrations are 100-199 $\mu \mathrm{g} / \mathrm{L}$ in children and adults, and $150-249 \mu \mathrm{g} / \mathrm{L}$ in pregnant women [7] [8]. Lower values than $100 \mu \mathrm{g} / \mathrm{L}$ indicate suboptimal iodine intake. Dietary sources of iodine are seaweed, seafood, dairy products, milk, beans, and eggs [9]. It is also present in breast milk as potassium iodide or sodium iodide, infant formula, and some multivitamins [10] [11] [12]. Selenium, carnitine, myo-inositol, flavonoids, omega-3 polyunsaturated fatty acids, and resveratrol each affect thyroid function [12]. But, iodine remains the most crucial essential element for thyroid hormones, thyroxine (T4), and triiodothyronine (T3). These hormones regulate protein synthesis, enzymatic activity, and metabolic activity.

Iodine deficiency causes an enlargement of the thyroid, known as endemic goiter [13]. Thyroid enlargement may transform to nodular changes. Molecular pathways in the nodular process proceed with DNA mutagenesis as evidenced by somatic mutations in iodine-deprived euthyroid goiters [14]. Molecular mechanisms to explain mutagenesis and the formation of nodules during iodine deficiency have not been fully explained.

Molecular iodine is particularly effective against viruses. More than 80 years ago, it was shown that the vaccinia virus can be killed with a $3 \%$ tincture of iodine and indeed it was the most efficient antiseptic identified to destroy the poliovirus when used topically. These studies and observations show the power of molecular iodine as an antiviral agent [15].

Iodine has shown virucidal activities against SARSCoV-2. A few publications are available on the quick deactivating action of povidone-iodine (PVP-1) on COVID-19. Povidone-iodine has been observed to have rapid and efficient antiviral activity. This activity is believed to be sufficient as a preventive measure against COVID-19. It may deactivate the virus when it is used for hand-skin-oral sanitizing and oral-nasal cleaning [16] [17].

Oral and nasal sprays with antiviral activity against SARS-CoV-2 are being studied, with povidone-iodine being 
one of the more promising substances. Intranasal PVP-I spray is active against SARS-CoV-2, as well as SARS$\mathrm{CoV}$ and the Middle East Respiratory Syndrome (MERS) (https://www.news-medical.net/news/20210719/Iodine-deriv ative-kills-SARS-CoV-2-within-90-sec.aspx). Povidoneiodine (PVP-I) $0.5 \%$ mouth rinse/gargle for $30 \mathrm{~s} \mathrm{can} \mathrm{reduce}$ SARS-CoV-2 virus infectivity to below detectable levels [18]. PVP-I can interrupt SARS-CoV-2 attachment to oral and nasopharyngeal tissues and lower the number of viral particles in the saliva and respiratory droplets [18].

Povidone-iodine mouthwash, gargle, and nasal spray have been shown to reduce nasopharyngeal viral load in patients with COVID-19 in other studies [19] [20].

Substantial reductions in the viral titer by iodine- $\mathrm{V}$ in essential iodine drops (EID) have been reported [21]. Iodine$\mathrm{V}$ in EID is effective at inactivating the virus in vitro and therefore could be applied intra-nasally to reduce SARSCoV-2 transmission from COVID-19-infected individuals. Iodine-V is likely to work better in vivo when compared with PVP-I against SARS-CoV-2 [21].

Use of povidone-iodine solution as SARS-CoV-2 prophylaxis for procedures of the upper aero-digestive tract has been suggested [22], as the nasopharynx and nasal and oral cavities act as a reservoir for SARS-CoV-2 shedding, and the application of viricidal agents to these surfaces reduce virus burden [22].

The virucidal effect of PVP-I on COVID-19 replication in the nasopharynx has been reported in other studies such as [23] [24].

PVP-I studies do not support any supplementation with dietary iodine to help against infection and disease, which is presently an unstudied area of research.

Thyroid nodules (TNs) are distinct lesions present in the thyroid itself, separate from the surrounding parenchyma [25]. TNs are 4 times more common in women than men. Their frequency increases with age and low iodine intake. Most TNs are benign, but about 5\% are cancerous [26].

A healthy thyroid depends on the optimal intake of dietary iodine which is necessary for the synthesis and metabolism of hormones produced by the thyroid. Sufficient thyroid hormone accumulation requires the action of hydrogen peroxide. Peroxide serves as the starting compound to produce reactive oxygen species (ROS). Production of hydrogen peroxide $\left(\mathrm{H}_{2} \mathrm{O}_{2}\right)$ is certainly hampered by the presence of iodide in vivo and in vitro [27] [28]. $\mathrm{H}_{2} \mathrm{O}_{2}$ is a unique general toxin, stable in abiotic environments at ambient temperature and neutral $\mathrm{pH}$, but able to quickly eradicate cells by manufacturing highly reactive hydroxyl radicals. Thyrocytes have an excellent ability to control oxidative stress. A high concentration of antioxidant enzyme, e.g., esp superoxide dismutase (SOD)-3, can protect the thyroid from the toxic effect of metabolites that originate from hydrogen peroxide. Significant iodine deficiency can impair thyroid hormone production and results in ROS-induced DNA damage. Iodine promotes thyroid health, reduces the risk for some goiters, manages the overactive thyroid gland, may improve cognitive function, and protects the thyroid gland from radiation injuries. It may also help treat fibrocystic breast disease [29]. Dietary iodine controls its absorption through the regulation of the sodium/iodide (NIS) symporter [30] [4] which protects the functions of the thyroid gland [31].

The link between vaccines and their impact on thyroid disorders is poorly investigated and limited to very few studies [32-35].

Vaccines may trigger local and systemic inflammatory responses (examples, myocarditis and pericarditis after mRNA COVID-19 vaccination). Vaccines may also have toxic effects caused by the presence of synthetic nucleosides and delivery components [36]. Specifically, some COVID-19 mRNA vaccines [37] [38] use lipid or polymerbased nanoparticles to protect and stabilize the mRNA and improve uptake. The toxicity of mRNA, non-replicating viral vectors, and other vaccines are only marginally assessed. In Australia [39], there have been 22,031 communications of adverse events from the administration of 3,613,053 shots of Pfizer and Astra-Zeneca vaccines (0.61\%). In between the adverse events, there have been 210 fatalities following vaccinations $(0.01 \%)$. These are non-negligible numbers and much larger than those of other vaccines such as the flu vaccine. Smaller numbers, based on a much larger database, but still non-negligible, are provided by the British Government (https://www.gov.uk/government/publications/coronaviruscovid-19-vaccine-adverse-reactions/coronavirus-vaccinesummary-of-yellow-card-reporting).

In addition, the efficacy of vaccines decreases with time and against variants.

The data on vaccinations and infections in Israel from December 2020 to July 2021, one of the countries with wider and quicker vaccinations with an mRNA vaccine, show that the vaccine's protection against infection and disease dropped from above $90 \%$ in the early months to about $40 \%$ with the delta variant a partial explanation [40] [41] (https://www.gov.il/BlobFolder/reports/vaccine-efficacysafety-follow-up-committee/he/files_publications_corona two-dose-vaccination-data.pdf) [42]. While vaccines are still effective in reducing hospitalizations, undoubtedly there is a reduced efficacy. This efficacy is greater with inactivated-virus vaccines (such as Seychelles) than DNA and mRNA vaccines [40]. Deployment of boosters [40] is a clear acknowledgment that the efficacy of vaccines is much less than $100 \%$, variable between vaccines, and decreases with time and variants. Therefore, there is a need for more attention toward different therapies.

Iodine binds well to toxins. Iodine also binds to metals such as aluminum and mercury. Iodine also helps thyroid functions, thus further contributing to detoxification. Iodine 
may be considered as one substance necessary to mitigate the adverse events from COVID-19 vaccines that could help also against COVID-19 infection. While the detoxification activity may in principle also limit the efficacy of vaccines, it is not expected that dietary supplementation to sufficiency could be an issue. The use of iodine supplements against viral effects has not been studied.

It is concluded that iodine-based products for mouthwash, gargle, and nasal spray may be useful to reduce nasopharyngeal viral load in patients with COVID-19.

Regarding iodine oral supplementation, there is no evidence supporting virucidal activity against COVID-19 infection, reduction of vaccine adverse events because of iodine supplementation, or reduction of the efficacy of vaccines because of iodine supplementation.

In lack of any contraindication, it is suggested to monitor the iodine level, by the simple and fast urine test, the more accurate blood test, or even the iodine patch test, and in case of deficit, adopt iodine supplementation.

Similarly to be considered is the use of iodine-based products for mouthwash, gargle, and nasal spray if and as directed by a physician.

Author Contribution The authors equally contributed to the writing of the letter.

Data Availability Not applicable.

\section{Declarations}

Ethics Approval Not applicable.

Research Involving Human Participants and/or Animals Not applicable.

Informed Consent Not applicable.

Consent for Publication Not applicable.

Conflict of Interest The authors declare that they have no conflict of interest.

\section{References}

1. Mourouzis I, Politi E and Pantos C (2013) Thyroid hormone and tissue repair: new tricks for an old hormone? J Thyroid Res 2013:312104

2. Kapil U (2007) Health consequences of iodine deficiency. Sultan Qaboos Univ Med J 7(3):267

3. Mei-li G, Lin L, Xin Z, Hong-mei S, Li-Xiang L, Jun YU, Xiaohong JI, Xue YU (2012) Influence of iodine on mRNA expression of iodide transporter, insulin-like growth factor I and transforming growth factor-beta in thyroid and mammary glands of lactating rats. Chin J Endemiol 31(3):245-250
4. Serrano-Nascimento C, Calil-Silveira J, Goulart-Silva F, Nunes MT (2012) New insights about the posttranscriptional mechanisms triggered by iodide excess on sodium/iodide symporter (NIS) expression in $\mathrm{PCCl} 3$ cells. Mol Cell Endocrinol 349(2):154-161

5. Haldimann M, Alt A, Blanc A, Blondeau K (2005) Iodine content of food groups. J Food Compos Anal 18:461-471

6. Vought RL, London WT (1967) Iodine intake, excretion and thyroidal accumulation in healthy subjects. J Clin Endocrinol Metab 27:913-919

7. World Health Organization, United Nations Children's Fund, International Council for the Control Iodine Deficiency Disorders (2007) Assessment of Iodine Deficiency Disorders and Monitoring Their Elimination, 3rd edn. World Health Organization, Geneva

8. Semba RD, Delange F (2001) Iodine in human milk: perspectives for human health. Nutr Rev 59:269-278

9. Hernando VU, Anilza BP, Hernan STC (2015) Iodine deficiency disorders. Thyroid Disord Ther 4:172

10. Azizi F, Smyth P (2009) Breastfeeding and maternal and infant iodine nutrition. Clin Endocrinol 70:803-809

11. Pearce EN, Pino S, He X, Bazrafshan HR, Lee SL, Braverman LE (2004) Sources of dietary iodine: bread, cows' milk, and infant formula in the Boston area. J Clin Endocrinol Metab 89:3421-3424

12. Montanelli L, Benvenga S, Vitti P, Latrofa F, Duntas LH (2018) Drugs and other substances interfering with thyroid function. In: Vitti P, Hegedus L (eds) Thyroid Diseases. Springer, Cham, pp 733-761

13. Delange FM (2003) Control of iodine deficiency in Western and Central Europe. Cent Eur J Public Health 11(3):120-123

14. Krohn K, Wohlgemuth S, Gerber H, Paschke R (2000) Hot microscopic areas of iodine-deficient euthyroid goitres contain constitutively activating TSH receptor mutations. J Pathol 192(1):37-42

15. Derry D (2009) Iodine: the forgotten weapon against influenza viruses. Thyroid Sci 4(8):R1-R5

16. Eggers M, Koburger-Janssen T, Eickmann M, Zorn J (2018) In vitro bactericidal and virucidal efficiency of povidone-iodine gargle/mouthwash against respiratory and oral tract pathogens. Infect Dis Ther 7(2):249-259. https://doi.org/10.1007/ s40121-018-0200-7

17. Eggers M, Eickmann M, Kowalski K, Zorn J, Reimer K (2015) Povidone-iodine hand wash and hand rub products demonstrated excellent in vitro virucidal efficacy against Ebola virus and modified vaccinia virus Ankara, the new European test virus for enveloped viruses. BMC Infect Dis 15:375. https://doi.org/10.1186/ s12879-015-1111-9

18. Sivaraman K, Radhakrishnan R, Balakrishnan D, Narayana A (2021) Can povidone Iodine gargle/mouthrinse inactivate SARS$\mathrm{CoV}-2$ and decrease the risk of nosocomial and community transmission during the COVID-19 pandemic? An evidence-based update. Jpn Dent Sci Rev 57:39-45

19. Guenezan J, Garcia M, Strasters D, Jousselin C, Lévêque N, Frasca D, Mimoz O (2021) Povidone iodine mouthwash, gargle, and nasal spray to reduce nasopharyngeal viral load in patients with COVID-19: a randomized clinical trial. JAMA Otolaryngol Head Neck Surg 147(4):400-401

20. Mimoz O and Seguin S (2020) Povidone iodine mouthwash, gargle, and nasal spray to reduce naso-pharyngeal viral load in patients with COVID-19. Cochrane Central Register of Controlled Trials (CENTRAL) 2020 Issue 05. www.cochranelibrary.com/ central/doi/10.1002/central/CN-02103651/full

21. Köntös Z (2021) Efficacy of "Essential Iodine Drops" against Severe Acute Respiratory Syndrome-Coronavirus 2 (SARSCoV-2). Plos one 16(7):e0254341 
22. Naqvi SH, Citardi MJ, Cattano D, Ostrosky-Zeichner L, Knackstedt MI, Karni RJ (2020) Povidone-iodine solution as SARS$\mathrm{CoV}-2$ prophylaxis for procedures of the upper aerodigestive tract a theoretical framework. J Otolaryngol Head Neck Surg 49(1):1-4

23. Hasan MJ, Rumi SNF, Banu SS, Uddin AN, Islam MS, Arefin MK (2021) Virucidal effect of povidone iodine on COVID-19 in the nasopharynx: a structured summary of a study protocol for an open-label randomized clinical trial. Trials 22(1):1-2

24. Arefin MK, Rumi SNF, Uddin AN, Banu SS, Khan M, Kaiser A, Chowdhury JA, Khan MAS, Hasan MJ (2021) Virucidal effect of povidone iodine on COVID-19 in the nasopharynx: an open-label randomized clinical trial. Indian J Otolaryngol Head Neck Surg $18: 1-5$

25. Delange F, Bürgi H, Chen ZP, Dunn JT (2002) World status of monitoring iodine deficiency disorders control programs. Thyroid 12:915-924

26. Gharib H, Papini E, Paschke R, Duick DS, Hegedus L et al (2010) American Association of Clinical Endocrinologists, Associazione Medicie Endocrinologi, and European Thyroid Association medical guidelines for clinical practice for the diagnosis and management of thyroid nodules: executive summary of recommendations. J Endocrinol Invest 33:51-56

27. Cardoso LC, Martins DC, Figueiredo MD, Rosenthal D, Vaisman M, Violante AH, Carvalho DP (2001) Ca2+/nicotinamide adenine dinucleotide phosphate-dependent $\mathrm{H} 2 \mathrm{O} 2$ generation is inhibited by iodide in human thyroids. J Clin Endocrinol Metab 86(9):4339-4343

28. Morand S, Chaaraoui M, Kaniewski J, Dème D, Ohayon R, NoelHudson MS, Virion A, Dupuy C (2003) Effect of iodide on nicotinamide adenine dinucleotide phosphate oxidase activity and Duox 2 protein expression in isolated porcine thyroid follicles. Endocrinology 144(4):1241-1248

29. https://www.healthline.com/health/iodine-uses (accessed April 21, 2021)

30. Nicola JP, Reyna-Neyra A, Carrasco N, Masini-Repiso AM (2012) Dietary iodide controls its own absorption through post-transcriptional regulation of the intestinal Na+/I- symporter. J Physiol 590(23):6013-6026

31. Li Q, Mair C, Schedle K, Hellmayr I, Windisch W (2013) Effects of varying dietary iodine supplementation levels as iodide or iodate on thyroid status as well as mRNA expression and enzyme activity of antioxidative enzymes in tissues of grower/finisher pigs. Eur J Nutr 52(1):161-168

32. Yu O, Bohlke K, Hanson CA, Delaney K, Rees TG, Zavitkovsky A, Ray P, Mullooly J, Black SB, Benson P, Thompson WW (2007)
Hepatitis B vaccine and risk of autoimmune thyroid disease: a Vaccine Safety Datalink study. Pharmacoepidemiol Drug Saf 16(7):736-745

33. Watad A, David P, Brown S, Shoenfeld Y (2017) Autoimmune/ inflammatory syndrome induced by adjuvants and thyroid autoimmunity. Front Endocrinol 7:150

34. Grimaldi-Bensouda L, Guillemot D, Godeau B, Bénichou J, Lebrun-Frenay C, Papeix C, Labauge P, Berquin P, Penfornis A, Benhamou PY, Nicolino M (2014) Autoimmune disorders and quadrivalent human papillomavirus vaccination of young female subjects. J Intern Med 275(4):398-408

35. Chalan P, Di Dalmazi G, Pani F, De Remigis A, Corsello A, Caturegli P (2018) Thyroid dysfunctions secondary to cancer immunotherapy. J Endocrinol Invest 41(6):625-638

36. Wang F, Kream RM, Stefano GB (2020) An evidence based perspective on mRNA-SARS-CoV-2 vaccine development. Med Sci Monit: international medical journal of experimental and clinical research 26:e924700-e924701

37. Editorial (2020) Nanomedicine and the COVID-19 vaccines. Nat Nanotechnol 15:963

38. Pardi N, Hogan MJ, Porter FW, Weissman D (2018) mRNA vaccines-a new era in vaccinology. Nat Rev Drug Discovery 17(4):261

39. Australian Therapeutic Goods Administration (TGA) (2021) COVID-19 vaccine weekly safety report 27-05-2021. www.tga.gov.au/periodic/covid-19-vacci ne-weekly-safety-report-27-05-2021

40. Callaway E (2021) COVID vaccine boosters: the most important questions. Nature 596, 178-180. www.nature.com/articles/ d41586-021-02158-6

41. Mizrahi B, Lotan R, Kalkstein N, Peretz A, Perez G, Ben-Tov A, Chodick G, Gazit S, Patalon T (2021) Correlation of SARS-CoV-2 breakthrough infections to time-from-vaccine; preliminary study. medRxiv. https://doi.org/10.1101/2021.07.29.21261317

42. Mallapaty S (2021) COVID vaccines slash viral spread - but Delta is an unknown. Nature 596, 17-18. www.nature.com/artic les/d41586-021-02054-z

Publisher's Note Springer Nature remains neutral with regard to jurisdictional claims in published maps and institutional affiliations. 